\title{
Quality Evaluation and Functional Properties of Reduced Sugar Jellies Formulated from Citrus Fruits
}

\author{
Ines Ben Rejeb $\mathbb{D}$, Nahla Dhen, Salma Kassebi, and Mohamed Gargouri $\mathbb{D}$ \\ Laboratory of Microbial Ecology and Technology, Biocatalysis and Industrial Enzymes Group, Carthage University, \\ National Institute of Applied Sciences and Technology (INSAT), BP 676 Tunis Cedex 1080, Tunis, Tunisia
}

Correspondence should be addressed to Ines Ben Rejeb; inesbenrejeb2504@gmail.com

Received 26 May 2020; Revised 7 September 2020; Accepted 7 October 2020; Published 20 October 2020

Academic Editor: Ioannis G. Roussis

Copyright $(92020$ Ines Ben Rejeb et al. This is an open access article distributed under the Creative Commons Attribution License, which permits unrestricted use, distribution, and reproduction in any medium, provided the original work is properly cited.

In Tunisia, despite the large annual production and the numerous citrus varieties under cultivation, citrus processing industries lack product diversity. Products based on dietary properties are a new trend aiming to develop innovative foods and to meet the requirements of the new customer class. In the present study, formulations of reduced sugar jelly products using antioxidant richfruit, citrus, were carried out. The effects of citrus juices on the jelly's antioxidant properties, colour, consistency, and sensory evaluation were also investigated. Results showed that all citrus jellies maintain their antioxidant activity, correlated with phenolic content presence. In fact, total phenolic contents ranged between 123.16 and $192.76 \mathrm{mg} \mathrm{GAE} / 100 \mathrm{~g}$, while flavonoid content varied between 1.54 and $9.06 \mathrm{mg}$ QE/100 g for grapefruit jelly and blood orange jelly, respectively. Results illustrated that antioxidant activity varies according to the variety. A sensory evaluation employing hedonic scale technique exhibited satisfactory acceptance of the reduced sugar blood orange and blond maltase jellies. These results highlight and promote the potential use of these citrus varieties in jelly industry as they present a rich source of phenolic compounds and may generate numerous phytochemicals with potential health promoting properties.

\section{Introduction}

Citrus fruits represent one of the most important cultivated plants, with a vast production which is estimated to be more than 120 million tons yearly across the world [1]. In Tunisia, according to the Ministry of Agriculture, the cultivation area occupied by these fruits was estimated to be around 25,000 ha with a yearly production of over 380.000 tons. An increase of $47 \%$ of citrus production was recorded in the last season. Such high production inevitably satisfies the fresh fruit market, the agro food sector, and the exportation demands. In addition to their delicious flavors, various characteristics of citrus fruits have been reported in the literature, namely, their antioxidant properties related to some health benefits. Citrus fruits have been also found to be dietary fiber-rich and contain various biocompounds such as flavonoids, vitamin $\mathrm{C}$, and phenolics. These compounds commonly act as free radical scavengers to regulate the activity of enzymes and also protect against various diseases [2].
Nowadays, antioxidants are compounds of highly importance due to their positive effects on health. In this regard, many conducted epidemiological studies have reported that the consumption of phenolics can indeed lower the risk of various diseases such as cardiovascular issues and cancer [3]. As a matter of fact, consuming juices made of citrus fruits or the fruits themselves can present many inhibitory activities against tumor, blood clot, inflammation, and fungus [4].

Given the fact that citrus availability is season-dependent, and due to their poor shelf life, citrus-derived products that preserve bioactive compounds, and some essential dietary micronutrients (minerals and vitamins) should be identified and considered $[5,6]$.

Preparation of citrus fruit-derived products such as juice, jam, jelly, and marmalade increase fruit shelf life and improve the accessibility of such products to the consumers all year round. Nevertheless, in Tunisia, citrus processing industries lack product diversity. So, in order to develop new 
products and exploit citrus overproduction, the potential use of Tunisian citrus varieties in jelly processing was investigated in this study.

According to the conventional codex, marmalades, jams, and jellies are characterized by a semisolid consistency and are prepared using the juice of the fruit and/or a liquid extract from one or more fruits [7]. The adequate texture requires a correct combination of each component. Furthermore, the manufacture of fruit jellies requires mostly the presence of sugar. It has a sweetening role and an important contribution to the gelation process and the obtainment of the desired texture. Therefore, any significant reduction of sugar content will definitely impact the end product [8].

In this study, sugar concentration in citrus jellies was reduced, thus allowing "reduced sugar" declaration. The first purpose of this work was to evaluate the quality parameters as well as the antioxidant property of four juices made out of citrus fruits. The second was to develop reduced sugar citrus jellies and to analyze their chemical, antioxidant, and overall acceptability. The performed study will allow a higher added-value exploitation of citrus fruits. Thus, growers, consumers, and processors can get maximum benefits, since it is highly recommended to encourage production of fruitprocessed products using local raw materials.

\section{Materials and Methods}

2.1. Plant Material. The study was performed using ripe fruits of four citrus varieties: blond maltese (Citrus sinensis), Maltaise demi-sanguine blood oranges (Citrus sinensis (L.) Osbeck), Bitter orange (Citrus aurantium), and Grapefruit (Citrus paradisi). Samples were harvested at their commercial maturity from the Cap-Bon region in the Northeast of Tunisia. For each variety, a fresh juice was extracted using a domestic juicer (Eurolux) and used for further analysis.

2.2. Jelly Formulation. Four citrus jellies, corresponding to the four citrus varieties, were prepared using the same procedure. Operating conditions were determined from preliminary studies. Jellies were prepared with a reduced amount of sucrose. Citrus juice ( $400 \mathrm{~mL})$, sucrose $(40 \mathrm{~g})$, and agar agar food-grade powder from Foodchem $(2 \mathrm{~g})$ were used for the jelly preparation. The mixture was cooked at $85^{\circ} \mathrm{C}$ into the open steel kettle under continuous stirring. Agar was added at the final stage of the jelly cooking and poured gently to avoid the formation of lumps. Citrus jelly mixture was heated until boiling to reach $27 \%-29 \%$ of soluble solids. The jelly samples were immediately versed into glass jars and then completely submerged in boiling water for five minutes. Containers were then left at room temperature and finally stored at $4^{\circ} \mathrm{C}$ for later analysis.

2.3. Titrable Acidity. Titrable acidity (TA) was measured according to the following volumetric method. Citrus juices were neutralized using $\mathrm{NaOH}$ solution $(0.1 \mathrm{~N})$, in the presence of some drops of phenolphthalein as an indicator. Indeed, under neutral conditions, sodium hydroxide solution turns the juice colour into pink [9].
TA of the jelly samples was estimated according to the method described by Sulieman et al. [10]. Samples were titrated with sodium hydroxide to $\mathrm{pH} 8.1$ using a $\mathrm{pH}$ meter.

Titrable acidity of juice and jelly samples was calculated, and results were expressed in grams of citric acid per liter.

2.4. Total Soluble Solids. The total soluble solids (TSSs) were defined as sugar content in \% and expressed as Brix [11]. This parameter was measured by a straightforward reading on the ATAGO refractometer (Atago 3810, Tokyo, Japan).

2.5. Polyphenol Extraction. Citrus juice extracts were prepared by mixing $1 \mathrm{~mL}$ of juice with $9 \mathrm{~mL}$ of $80 \%$ methanol. The extraction step was carried out at room temperature $\left(25 \pm 2^{\circ} \mathrm{C}\right)$ for $30 \mathrm{~min}$. The supernatant was recovered after centrifugation, for total phenolics, total flavonoids, and antioxidants activity determination $[12,13]$.

Jellies extracts were prepared by mixing one gram of sample with $80 \%$ methanol $(1: 5, \mathrm{w}: \mathrm{v})$ for $15 \mathrm{~min}$. After centrifugation, the obtained extracts were kept at $4^{\circ} \mathrm{C}$ until further analysis.

2.6. Total Phenolic Content Determination. Total phenolic content (TPC) was quantified following the method reported by Garrido et al. [14]. Sample extract $(100 \mu \mathrm{L})$ was mixed with $100 \mu \mathrm{L}$ of Folin-Ciocalteu's phenol reagent for $3 \mathrm{~min}$. Then, $1 \mathrm{ml}$ of $\mathrm{Na}_{2} \mathrm{CO}_{3}$ solution (20\%) was added, and the mixture was incubated during $30 \mathrm{~min}$ in the dark. Absorbance was measured at $750 \mathrm{~nm}$ versus a prepared blank. The standard curve was achieved using gallic acid. TPC was expressed as mg gallic acid equivalent per liter for the juice extract (mg GAE L ${ }^{-1}$ ) and per $100 \mathrm{~g}$ of jelly sample (mg $\mathrm{GAE} / 100 \mathrm{~g})$.

2.7. Total Flavonoid Content Determination. Total flavonoid content (TFC) was performed using the Dowd colorimetric method. Briefly, $1 \mathrm{~mL}$ of $2 \%$ aluminium trichloride methanolic solution was mixed with the same volume of the sample extract. The mixture was kept in the dark for $15 \mathrm{~min}$ and the absorbance measured at $415 \mathrm{~nm}$. The calibration curve was determined using quercetin as standard (from 5 to $\left.100 \mu \mathrm{g} / \mathrm{ml}, R^{2}=0.9949\right)$. Estimation of flavonoids was carried out in triplicate, and results were expressed as mg quercetin equivalents per liter for the juice extract $\left(\mathrm{mg} \mathrm{QE} \mathrm{L}^{-1}\right)$ and per $100 \mathrm{~g}$ of the jelly sample (mg QE/100 g).

\subsection{Antioxidant Activity}

2.8.1. DPPH Assay. The radical scavenging ability of the obtained extracts was assessed using the stable free radical DPPH (2, 2-diphenyl-1-picrylhydrazyl) according to the method described by Letaief et al. with some modifications [13]. Extract solutions $(30 \mu \mathrm{L})$ were mixed with $970 \mu \mathrm{L}$ of freshly prepared DPPH solution $(60 \mu \mathrm{M}$ in methanol). The mixture was shaken vigorously and left in the dark at room temperature for $30 \mathrm{~min}$. The reduction of the $\mathrm{DPPH}$ radical 
was determined by measuring the decrease of absorbance at $517 \mathrm{~nm}$. DPPH scavenging effect was calculated as follows:

$$
\% \mathrm{DPPH} \text { inhibition }=\left[\frac{\left(A_{0}-A_{1}\right)}{A_{0}}\right] \times 100,
$$

where $A_{0}$ is the absorbance of the DPPH solution and $A_{1}$ is the absorbance of the solution when the sample extract has been added. A calibration curve was performed using Trolox as a positive control and results were reported as millimolar of Trolox equivalents per liter for the juice extracts ( $\mathrm{mM} \mathrm{TE}$ $\mathrm{L}^{-1}$ ) and as micromol Trolox equivalents per $100 \mathrm{~g}$ of jelly samples ( $\mu \mathrm{mol} \mathrm{TE} / 100 \mathrm{~g})$.

2.8.2. ABTS Assay. The ABTS free radical assay is based on the capability of antioxidants to reduce $\mathrm{ABTS}^{+}$(blue/ green) generating ABTS-2 (colourless). The ABTS radical scavenging activity was determined according to the method described by Oboh et al. [15]. The ABTS radical cation solution was prepared by reacting $7 \mathrm{mM}$ ABTS aqueous solution with $\mathrm{K}_{2} \mathrm{~S}_{2} \mathrm{O}_{8}(2.45 \mathrm{mM})$ at a ratio $2: 2$ $(\mathrm{v} / \mathrm{v})$. The mixture was kept in the dark for 12 hours at room temperature, and then the absorbance at $734 \mathrm{~nm}$ was adjusted to $0.700 \pm 0.02$ with ethanol. Thereafter, adequate solutions of extract in methanol were prepared to obtain a final volume of $200 \mu \mathrm{L}$. Sample $(200 \mu \mathrm{L})$ was mixed with $2 \mathrm{~mL} \mathrm{ABTS}{ }^{+}$solution, and the mixture was kept for $15 \mathrm{~min}$ in the dark. The absorbance was then measured at 734 . The radical scavenging activity was calculated as follows:

$$
\begin{aligned}
\text { percentage inhibiting activity, } I \%= & \left(A_{\text {control }}-A_{\text {sample }}\right) \\
& \times \frac{100}{A_{\text {control }}},
\end{aligned}
$$

where $A_{\text {control }}$ is the absorbance of control and $A_{\text {sample }}$ is the absorbance of the sample. Trolox equivalent antioxidant activity was subsequently determined using Trolox as a positive control. ABTS radical cation scavenging activities were expressed as TEAC.

\subsection{Textural Measurements}

2.9.1. Consistency. The flow distance of a controlled jelly sample weight for a constant time was determined using a Bostwick consistometer-p27460, Camlab, UK. This instrument consists of a level stainless-steel trough split into two separated compartments. The first one $(5 \times 5 \times 3.8 \mathrm{~cm})$ initially contains the sample. The second compartment $(5 \times 24 \times 2.5 \mathrm{~cm})$ has a series of parallel lines drawn across the floor at $0.5 \mathrm{~cm}$ intervals. The first compartment is separated from the second one by means of a spring-loaded gate. Once the gate is opened, the flow distances are measured after $30 \mathrm{~s}$. To measure the consistency, the distance advanced by the jellies in the related to their weight was calculated (millimetres per gram) [16].
2.9.2. Viscosity Analyses. Viscosity measurements were carried out using a viscometer Brookfield dv-ii (Brookfield, Middleboro, USA). About $80 \mathrm{~g}$ of jelly was put into the rheometer cup. The viscosities of the products were measured at $20^{\circ} \mathrm{C}$ by applying a rotation speed of 100 rotations/ $\min$.

2.10. Colour Evaluation. Colour parameters of citrus jellies were determined by colorimeter Minolta (Minolta, CM 3600D, Tokyo, Japan). An aliquot of each sample was taken, and the total colour transmitted through the sample was measured at $10^{\circ}$ observer and D65 illuminant. L* represents the lightness, $\mathrm{a} *$ represents the chromaticity on a green $(-)$ to red $(+)$ axis, and $\mathrm{b} *$ represents chromaticity on a blue $(-)$ to yellow $(+)$ axis. Samples were also analyzed according to their chroma values, $\mathrm{C} *=(\mathrm{a} * 2+\mathrm{b} * 2) 1 / 2$, which indicates the intensity or colour saturation, and hue angle, $\mathrm{h} *$ $\left(0-360^{\circ}\right)$, obtained by $\tan ^{-1} \mathrm{~b} * / \mathrm{a} *$ [17].

2.11. Sensory Evaluation. Sensory evaluation for jellies was performed by a panel of 45 students ( 22 males and $23 \mathrm{fe}$ males) of the National Institute of Applied Science and Technology (INSAT). Jellies were evaluated based on the acceptance of their flavor, acidity, texture, colour, odour, and overall acceptability on a 5-point hedonic scale. The scale of values ranged from "extremely dislike" (score 1) to "like extremely" (score 5). Jellies were prepared one day before analysis and were warmed at room temperature. Samples were served to the panelists in plastic plates $(20 \mathrm{~g})$ coded with random three-digit numbers. Before analysis, panelists were instructed to rinse their mouths with water after each sample tasting in order to minimize residual flavor effects.

2.12. Statistical Analysis. Statgraphics Centurion XVI software (StatPoint Technologies, Warrenton, USA) was used to perform analysis of variance (ANOVA) and to study differences between measurements. Fisher's least significant difference (LSD) test was used to describe means with a confidence level of 95\% $(p<0.05)$. Pearson coefficients were determined to evaluate correlations between phenolic compound contents and antioxidant activities in juices and jellies and between antioxidant activities and colour parameters.

\section{Results and Discussion}

3.1. Quality Parameters of Citrus Juices. Quality parameters, including juice yield, $\mathrm{pH}, \mathrm{TA}$, TSS, and TSS/TA ratio of citrus juices were carried out. Results are shown in Table 1.

For juice yield, results varied considerably according to citrus varieties and values were ranged between $26.81 \%$ for bitter orange and $46.30 \%$ for blood orange. In the literature, it is noteworthy that the reported juice yield levels varied between 26.95 and $60.74 \%$. For several citrus varieties, the content of juice determines their harvested period [9].

Regarding $\mathrm{pH}$, values ranged from 2.67 for bitter orange to 3.47 for blood orange. $\mathrm{pH}$ is an important parameter for 
TABLE 1: Juice yield, pH, total soluble solids (TSSs), titrable acidity (TA), and TSS/TA ratio of juices of blond maltese, blood orange, grapefruit, and bitter orange.

\begin{tabular}{|c|c|c|c|c|c|}
\hline \multirow{2}{*}{ Citrus cultivars } & \multicolumn{5}{|c|}{ Quality parameters } \\
\hline & Juice yield (\%) & $\mathrm{pH}$ & TSS $\left({ }^{\circ}\right.$ Brix $)$ & TA $\left(\mathrm{g} \mathrm{L}^{-1}\right)$ & TSS/TA ratio \\
\hline Blond maltese & $45.92 \pm 0.68^{\mathrm{c}}$ & $3.34 \pm 0.02^{\mathrm{c}}$ & $12.66 \pm 0.08^{\mathrm{d}}$ & $14.14 \pm 0.08^{\mathrm{c}}$ & $8.95 \pm 0.03^{c}$ \\
\hline Blood orange & $46.30 \pm 0.44^{\mathrm{c}}$ & $3.47 \pm 0.03^{\mathrm{d}}$ & $11.20 \pm 0.20^{\mathrm{b}}$ & $8.67 \pm 0.04^{\mathrm{a}}$ & $12.91 \pm 0.18^{\mathrm{d}}$ \\
\hline Grapefruit & $44.02 \pm 0.56^{\mathrm{b}}$ & $3.02 \pm 0.02^{\mathrm{b}}$ & $9.53 \pm 0.05^{\mathrm{a}}$ & $11.83 \pm 0.09^{\mathrm{b}}$ & $8.05 \pm 0.02^{b}$ \\
\hline Bitter orange & $26.81 \pm 0.44^{\mathrm{a}}$ & $2.67 \pm 0.06^{\mathrm{a}}$ & $11.50 \pm 0.01^{\mathrm{c}}$ & $45.6 \pm 1.5^{\mathrm{d}}$ & $2.52 \pm 0.03^{\mathrm{a}}$ \\
\hline
\end{tabular}

Means followed by a different letter in the same column are significantly different $(p<0.05)$.

citrus juice preservation. Indeed, higher $\mathrm{pH}$ value leads to a microbial stability reduction [13].

Grapefruit had the lowest TSS value $\left(9.53^{\circ}\right.$ Brix $)$ followed by blood orange $\left(11.2^{\circ} \mathrm{Brix}\right)$, while blonde Maltaise had the highest value $\left(12.66{ }^{\circ} \mathrm{Brix}\right)$.

TA of bitter orange was the highest $\left(45.6 \mathrm{~g} \mathrm{~L}^{-1}\right)$, whereas blood orange had the lowest value $\left(8.672 \mathrm{~g} \mathrm{~L}^{-1}\right)$.

Maturity index was determined by the TSS/TA ratio and was related to citrus fruit quality. TSS/TA ratio value, usually used to estimate the feasible harvesting time, is closely dependent to citrus variety [11]. Results showed that blood orange had the highest TSS/TA value, whereas bitter orange had the lowest one.

\subsection{Total Phenolic (TPC) and Total Flavonoid Content (TFC)} of Citrus Juices. The TPCs of juice extracts are recapitulated in Table 2. Results showed that phenolic contents of juices varied according to species and values ranged between 319.27 and $786.85 \mathrm{mg} \mathrm{GAE} \mathrm{L}^{-1}$. Blood orange juice had the highest phenolic content (786.85 $\mathrm{mg} \mathrm{GAE} \mathrm{L}^{-1}$ ), followed by blond maltese (544.28 $\mathrm{mg} \mathrm{GAE} \mathrm{L}^{-1}$ ) while grapefruit had the lowest amount (319.27 $\mathrm{mg} \mathrm{GAE} \mathrm{L}^{-1}$ ). The obtained TPC in the present study is in agreement with that given by Rapisarda et al. [18] where moderate phenol contents were highlighted (507.13 mg GAE L ${ }^{-1}-696.43 \mathrm{mg} \mathrm{GAE} \mathrm{L}^{-1}$ ) in five Italian orange genotypes. The above results may be justified by the implication of several factors such as climatic conditions, practical conditions, and origin as well as the chosen cultivar and organ.

Otherwise, TFCs varied also depending on the variety. They ranged between $13.95 \mathrm{mg} \mathrm{EQ} \mathrm{L}^{-1}$ and $86.64 \mathrm{mg} \mathrm{EQ} \mathrm{L}^{-1}$ (Table 2). We noticed that blood orange was richer than blond maltese regarding flavonoid content. Obtained results were different from those found by Tounsi et al. [12] who mentioned TFC of 34.68 and $67.8 \mathrm{mg} \mathrm{EC} \mathrm{L}^{-1}$ for blood orange and bitter orange juices, respectively, whereas our findings agrees with those previously observed by Rapisarda et al. [18] who reported the same behaviors for blood oranges (Moro, Tarocco, and Sanguinello). These sweet orange varieties are the most cultivated in Italy and have the same flesh and rind colour, given the red pigments classified as anthocyanins. Also, the above varieties have higher levels of vitamin $\mathrm{C}$, hydroxycinnamic acids, and flavanones than blond orange varieties.

3.3. Antioxidant Activities of Citrus Juices. In this study, we applied two complementary methods, namely, DPPH and ABTS, based on similar antioxidant mechanism for evaluating antioxidant activities of the studied extracts. The cationic $\mathrm{ABTS}^{+}$radical scavenging effects showed that blood orange juice exhibited higher antiradical potential than blond maltese, bitter orange, and grapefruit (values were 8.85 $\mathrm{mM} \mathrm{TE} \mathrm{L}^{-1}, 6.57 \mathrm{mM} \mathrm{TE} \mathrm{L} \mathrm{L}^{-1}, 6.21 \mathrm{mM} \mathrm{TE} \mathrm{L}^{-1}$, and $5.49 \mathrm{mM} \mathrm{TE} \mathrm{L}^{-1}$, respectively) (Table 2 ).

In the case of DPPH free radical scavenging assay, the antioxidant activity of citrus juices showed similar trends and values varied with respect to species between $28.52 \%$ and $51.71 \%$. As for the ABTS test, blood orange juice reached the highest antioxidant potential ( $3.19 \mathrm{mM} \mathrm{TE} \mathrm{L}^{-1}$ of juice). These results are comparable to those determined by Xu et al. [19] for Chinese citrus juices. The authors found that degrees of DPPH scavenging activities are ranged between $23.69 \%$ (Manju) and 60.24\% (Hamlin).

Citrus species' antioxidant activities are often positively correlated with their TPC. Thus, a comparison between, on one hand, blond maltese, grapefruit, and bitter orange juices, and, on the other hand, blood orange juice shows that this latter contains higher phenolic acids and flavonoid content. This leads consequently higher antioxidant activity. Pearson correlation coefficients between phenolic compound contents and antioxidant activities in orange juices were calculated (data not shown). Results demonstrate that the ABTS test for juices is correlated with their composition in flavonoids and polyphenols. Results showed also correlation between polyphenols contents and DPPH radical scavenging potential in juices $(r=0.9089)$. In this context, several works showed that phenolic content and antioxidant activity are highly correlated [20].

3.4. Quality Parameters of Jellies. Many factors affect the composition of plants and fruits, mainly variety, maturity stage, growth, climatic conditions, and soil type. Citrus fruit' composition affects in turn jellies' properties. Physical and chemical properties of formulated citrus jellies are given in Table 3. Acidity degree of jelly products affects inherent jelly properties, namely, taste, texture, colour, and flavor. Low $\mathrm{pH}$ values of citrus juices yield higher jelly stability. The $\mathrm{pH}$ values varied between 2.74 for bitter orange jelly and 3.56 for blood orange jelly. Furthermore, $\mathrm{pH}$ values of all the products were less than 3.5 , which would maintain inherent microbiological stability, as was highlighted in other fruitderived products prepared with peach strawberry, apricot, plum, and lemon [21]. The jelly samples were analyzed for acidity, and values ranged between $6.15 \mathrm{~g} \mathrm{~L}^{-1}$ and $42.76 \mathrm{~g}$ $\mathrm{L}^{-1}$. 
TABLE 2: The antioxidant capacity (ABTS and DPPH methods) and total phenolic and flavonoid assessment in citrus juices and their derived jellies.

\begin{tabular}{lcccccccc}
\hline Cultivars & $\begin{array}{c}\text { Polyphenol } \\
\text { content } \\
(\mathrm{mg} \mathrm{GAE} / \mathrm{L})\end{array}$ & $\begin{array}{c}\text { Flavonoid } \\
\text { content } \\
(\mathrm{mg} \mathrm{EQ} / \mathrm{L})\end{array}$ & $\begin{array}{c}\text { ABTS } \\
(\mathrm{mM} \mathrm{TE} / \mathrm{L})\end{array}$ & $\begin{array}{c}\text { DPPH } \\
(\mathrm{mM} \mathrm{TE} / \mathrm{L})\end{array}$ & $\begin{array}{c}\text { Polyphenol } \\
\text { content } \\
(\mathrm{mg} \mathrm{GAE} / 100 \mathrm{~g})\end{array}$ & $\begin{array}{c}\text { Flavonoid } \\
\text { content } \\
(\mathrm{mg} \text { EQ/100 g) }\end{array}$ & $\begin{array}{c}\text { ABTS } \\
(\mu \mathrm{mol} \mathrm{TE} / 100 \mathrm{~g})\end{array}$ & $\begin{array}{c}\text { DPPH } \\
(\mu \mathrm{mol} \text { TE/100 g) }\end{array}$ \\
\hline $\begin{array}{l}\text { Blond } \\
\text { maltese }\end{array}$ & $544.28 \pm 43.95^{\mathrm{b}}$ & $13.95 \pm 0.80^{\mathrm{a}}$ & $6.57 \pm 0.30^{\mathrm{a}}$ & $2.86 \pm 0.02^{\mathrm{c}}$ & $154.98 \pm 21.63^{\mathrm{b}}$ & $1.66 \pm 0.19^{\mathrm{ab}}$ & $498.40 \pm 12.45^{\mathrm{b}}$ & $188.13 \pm 12.40^{\mathrm{b}}$ \\
$\begin{array}{l}\text { Blood } \\
\text { orange }\end{array}$ & $786.85 \pm 20.00^{\mathrm{c}}$ & $86.64 \pm 1.13^{\mathrm{c}}$ & $8.85 \pm 0.36^{\mathrm{b}}$ & $3.19 \pm 0.10^{\mathrm{c}}$ & $192.76 \pm 9.27^{\mathrm{c}}$ & $9.06 \pm 0.26^{\mathrm{c}}$ & $807.70 \pm 14.42^{\mathrm{c}}$ & $257.05 \pm 16.40^{\mathrm{c}}$ \\
$\begin{array}{l}\text { Grapefruit } \\
\text { Bitter } \\
\text { orange }\end{array}$ & $319.27 \pm 36.56^{\mathrm{a}}$ & $30.10 \pm 1.04^{\mathrm{b}}$ & $5.49 \pm 0.25^{\mathrm{a}}$ & $1.84 \pm 0.12^{\mathrm{a}}$ & $123.16 \pm 12.02^{\mathrm{a}}$ & $1.54 \pm 0.15^{\mathrm{a}}$ & $314.90 \pm 23.79^{\mathrm{a}}$ & $73.07 \pm 5.08^{\mathrm{a}}$ \\
\hline
\end{tabular}

Each value is expressed as mean value \pm standard deviation $(n=3)$. Means followed by a different letter in the same column are significantly different $(p<0.05)$.

TABle 3: pH, ${ }^{\circ}$ Brix, titrable acidity (TA), and flow distance of formulated jellies.

\begin{tabular}{lccccc}
\hline & $\mathrm{pH}$ & TA $\left(\mathrm{g} \mathrm{L}^{-1}\right)$ & Brix $(\%)$ & Distance/weight $(\mathrm{mm} / \mathrm{g})$ & Viscosity $($ poise $)$ \\
\hline Blond maltese jelly & $3.46 \pm 0.12^{\mathrm{c}}$ & $11.97 \pm 1.12^{\mathrm{b}}$ & $27.33 \pm 0.45^{\mathrm{b}}$ & $0.0123 \pm 0.0015^{\mathrm{a}}$ & $25.2 \pm 2.70^{\mathrm{a}}$ \\
Blood orange jelly & $3.56 \pm 0.04^{\mathrm{d}}$ & $6.15 \pm 0.05^{\mathrm{a}}$ & $28.42 \pm 1.01^{\mathrm{c}}$ & $0.0116 \pm 0.0015^{\mathrm{a}}$ & $56.6 \pm 3.31^{\mathrm{b}}$ \\
Grapefruit jelly & $3.11 \pm 0.03^{\mathrm{b}}$ & $9.88 \pm 1.04^{\mathrm{b}}$ & $28.05 \pm 0.64^{\mathrm{c}}$ & $0.012 \pm 0.001^{\mathrm{a}}$ & $76.0 \pm 11^{\mathrm{c}}$ \\
Bitter orange jelly & $2.74 \pm 0.05^{\mathrm{a}}$ & $42.76 \pm 1.64^{\mathrm{c}}$ & $26.93 \pm 0.09^{\mathrm{a}}$ & $0.0121 \pm 0.0009^{\mathrm{a}}$ & $75.0 \pm 9.20^{\mathrm{c}}$ \\
\hline
\end{tabular}

Each value is expressed as mean values \pm standard deviation $(n=3)$. Means followed by a different letter in the same column are significantly different $(p<0.05)$.

Normal fruit conserves or preserves must contain $\geq 60 \%$ total soluble solids [7]. Normal jellies are characterized with low $\mathrm{pH}$ values and high sugar content; this brings high stability levels for such jellies and enables to store them at room temperature with a minimum risk that microbial degradation and chemical changes will affect their sensory quality. Total soluble solids (TSSs) of formulated jellies ranged from 26.93 to $28.42{ }^{\circ}$ Brix. The relatively low TSS content was a consequence of the low sucrose proportion used. Since sugar consumption is directly related to diabetes and other illnesses such as obesity, consumers around the world are being more aware about the relationship between disease risk and dietary habits; therefore, reduced-calorie jelly production have been investigated in the literature in order to develop low glycemic foods [22]. Table 3 gives the values of flow distance of a jelly sample for a fixed time interval (30 seconds). No significant differences have been noticed between citrus jellies. Jelly consistencies hamper sample flow in the consistometer. These structures are probably due to the use of agar as a gelling agent. Similar results reported by Igual et al. [16] showed that high grapefruit jam consistency is likely a consequence of the high pectin solubilisation.

According to the viscosity, which is a measure of a fluid's resistance to flow, results in Table 3 show that bitter orange jelly exhibits the highest value (76 Poise) and grapefruit jelly the lowest one (25.20 Poise). The viscosity measurements showed a difference among jellies which can be explained by the difference in citrus varieties, essentially due to the fruit initial content in sugar.

\subsection{Total Phenolic and Total Flavonoid Contents of Citrus} Jellies. Phenolic compounds are the most plentiful antioxidants in human diet and widespread constituents of fruits and vegetables. These compounds are of paramount interest, given their antioxidant virtues. Citrus jellies were investigated for their TPC, and the results are illustrated in Table 2. Jelly samples showed significant differences between each other, and values ranged between 123.16 and $192.76 \mathrm{mg} \mathrm{GAE} / 100 \mathrm{~g}$. TPC in our study was higher than that reported by Kopjar et al. [6] for orange jelly and orange jelly with trehalose addition $(1185.65$ and $1050.32 \mathrm{mg}$ GAE $/ \mathrm{kg}$, respectively). On the other hand, citrus flavonoids are considered among possible cancer preventing agents and include a large number of different molecules which may result in diverse biological activities. However, the literature available is poor in references about determination of flavonoid content in citrus-derived products. From the obtained results, significant differences between jelly samples were observed. The content of these bioactive compounds ranged between 1.54 and $9.06 \mathrm{mg} \mathrm{EQ} / 100 \mathrm{~g}$ for grapefruit jelly and blood orange jelly, respectively.

Polyphenol and flavonoid contents in jellies are highly correlated to those obtained in juice samples $(r=0.9697$ and $r=0.8224$, respectively).

3.6. Evaluation of Antioxidant Activities of Citrus Jellies. Antioxidant capacity of both fruits and fruit jellies is closely related to the phenolic compound content; the latter could be harmfully affected by physical-chemical factors related to food processing. As expected, antioxidant activity obtained for jelly samples exhibited the same trends as the respective citrus juices. Results showed that the abilities of jellies to scavenge $\mathrm{ABTS}^{+}$and $\mathrm{DPPH}$ radicals were significantly different (Table 2 ). Blood orange jelly reached the highest antioxidant capacity. Generally, fruit products with higher red colour intensity 
TABLE 4: Colour parameters of formulated jellies.

\begin{tabular}{|c|c|c|c|c|c|}
\hline Jellies & $\mathrm{L}^{*}$ & $a^{*}$ & $b^{*}$ & $\mathrm{~h}^{*} \mathrm{ab}$ & Cvab \\
\hline Blond maltese jelly & $36.74 \pm 1.02^{\mathrm{b}}$ & $17.08 \pm 0.21^{\mathrm{c}}$ & $15.08 \pm 0.29^{c}$ & $41.40 \pm 0.19^{\mathrm{b}}$ & $22.78 \pm 0.36^{\mathrm{C}}$ \\
\hline Blood orange jelly & $23.50 \pm 0.37^{\mathrm{a}}$ & $21.1 \pm 1.74^{\mathrm{d}}$ & $5.54 \pm 0.18^{\mathrm{a}}$ & $14.72 \pm 0.7^{\mathrm{a}}$ & $21.81 \pm 1.73^{\mathrm{c}}$ \\
\hline Grapefruit jelly & $35.21 \pm 0.19^{\mathrm{b}}$ & $6.83 \pm 0.30^{\mathrm{b}}$ & $10.17 \pm 0.50^{\mathrm{b}}$ & $56.07 \pm 0.89^{c}$ & $12.24 \pm 0.56^{\mathrm{b}}$ \\
\hline Bitter orange jelly & $51.23 \pm 1.19^{c}$ & $1.50 \pm 0.25^{\mathrm{a}}$ & $9.21 \pm 0.83^{\mathrm{b}}$ & $79.66 \pm 2.13^{\mathrm{d}}$ & $9.33 \pm 0.79^{\mathrm{a}}$ \\
\hline
\end{tabular}

Values are means of three replicates. $\mathrm{L}$ (lightness: $0=$ black, $100=$ white), a (greenness $(-)$, redness $(+)$ ), and b (blueness $(-)$, yellowness $(+)$ ). Within the same column, means followed by different letters are significantly different $(p<0.05)$.

had greater antioxidant activity. The high antioxidant activity detected in such products is very likely related to anthocyanin presence [23].

The antioxidant activities of citrus jellies, determined by DPPH method, ranged between $73.07 \mu \mathrm{mol} \mathrm{TE} / 100 \mathrm{~g}$ for grapefruit jelly and $257.05 \mu \mathrm{mol} \mathrm{TE} / 100 \mathrm{~g}$ for blood orange jelly. Our results are considerably higher than those presented in a previous study [6]. These latter estimated an antioxidant activity in orange jelly of $0.549 \mu \mathrm{mol} \mathrm{TE} / 100 \mathrm{~g}$ using the DPPH method, while this activity was of $0.522 \mu \mathrm{mol} \mathrm{TE} / 100 \mathrm{~g}$ when ABTS method was used.

The antioxidant activity determined by the ABTS method had similar tendency and values ranged from $314.90 \mu \mathrm{mol} \mathrm{TE} / 100 \mathrm{~g}$ for grapefruit jelly to $807.70 \mu \mathrm{mol} \mathrm{TE} /$ $100 \mathrm{~g}$ for blood orange jelly. Our findings are close to those described by Bof et al. for pear, fig, apple, and grape jellies (TEAC values were $400,500,550$, and $1000 \mu \mathrm{mol} / 100 \mathrm{~g}$ of jelly, respectively) [23]. ABTS assay in jellies showed correlation with polyphenol $(r=0.915)$ and flavonoid contents $(r=0.7962)$ in juices and with polyphenol content in jellies $(r=0.9139)$. This indicates that these compounds are major responsible for free radical scavenging ability of jellies.

Nevertheless, there is no tangible correlation between $\mathrm{DPPH}$ and flavonoid content in juices.

In addition, no correlation was noted between DPPH test in jellies and flavonoid content in juices, which suggests that antioxidant activity depends not only on the content of phenolic compounds but also on their natures and structures.

3.7. Evaluation of Colour Parameters. Manufacturing processes, namely, drying, dilution, and baking may affect final fruit product colour. Since the latter is one of the main factors of fruit product quality, consumers use it to evaluate the visual quality and acceptability of foodstuff.

Results showed that colour parameters of formulated jellies mainly depend on the citrus juice used as raw material (Table 4). Significant differences were found in colour values of analyzed jellies. $\mathrm{L} *$ values ranged from 23.50 for blood orange jelly to 51.23 for bitter orange jelly. For a* value, all the samples showed positive $a *$ values, indicating that formulated citrus jellies possess reddish colour. A significant negative correlation was calculated between $\mathrm{L} *$ and polyphenol, $\mathrm{L} *$ and ABTS, and $\mathrm{L} *$ and DPPH (data not shown). With regard to $\mathrm{b} *$ values, they ranged from 5.54 to 15.08 , which indicated that citrus jellies lean more towards yellowish colour. $\mathrm{b} *$ is negatively correlated with flavonoid contents. Thus, overall, positive $\mathrm{a} *$ and $\mathrm{b} *$ values result in an orange hue.

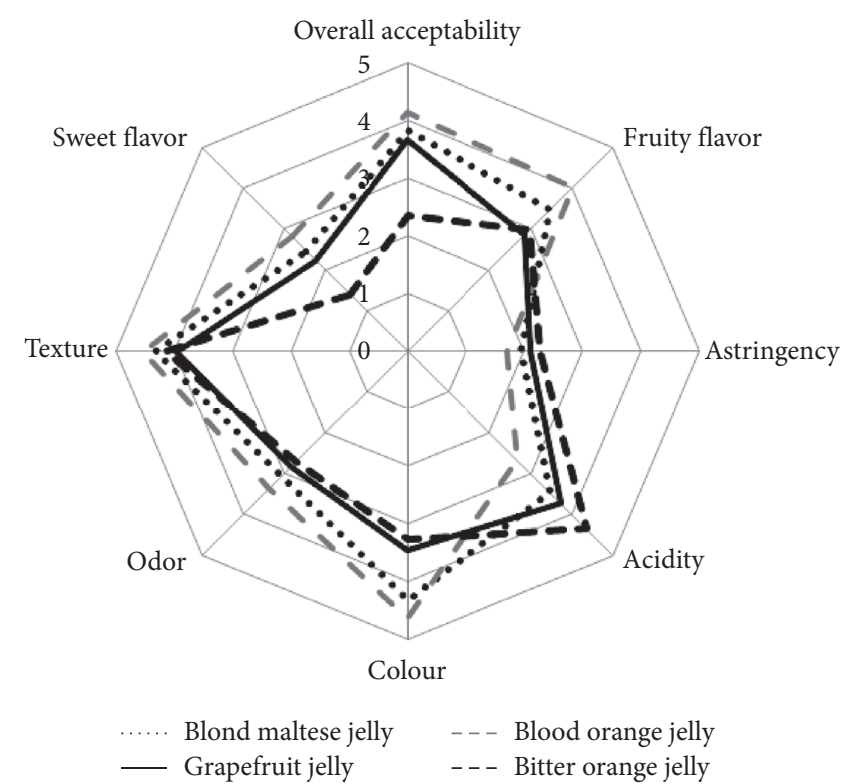

Figure 1: Sensory profile of citrus jellies.

Results showed that bitter orange jelly exhibited lighter colour (highest $\mathrm{L} *$ ) and lower redness (lowest $\mathrm{a} *$ ) than the other citrus jellies. These findings can be attributed to its high acid citric content as mentioned by Abd El-hady, who showed that the pretreatment of frozen strawberry with citric acid promoted the colour improvement mainly lightness [24].

Generally, obtained chroma values exhibited the same trends. Since chroma reflects colour brilliance or purity and is correlated with the content of anthocyanin, it will increase with pigment concentration. Indeed, formulated blond maltese and blood orange jellies had the highest chroma value.

Otherwise, the hue of bitter orange jelly would be significantly the highest compared to the other jellies samples which, in relation with a comparatively low chroma value, describe the yellowish colour.

3.8. Sensory Evaluation. Organoleptic evaluation is one of the key factors for both new product development and food quality control. Food quality is determined through complex sensation resulting from the interaction of different senses (smell, taste, and touch...). Figure 1 shows average scores for each evaluated attribute through radial chart representation. ANOVA results (data not shown) demonstrated significant differences in overall acceptability, fruity flavor, 
acidity, odour, colour, and sweetness between jelly samples. However, no statistical differences in texture were detected. Average scores of overall acceptability ranged from 2.36 to 4.13 in the 5-point hedonic scale. The jelly having the highest average acceptability score (preferred sample) was prepared using blood orange juice. The obtained score for bitter orange jelly $(<3)$ suggests that additional work is required to improve the formulated jelly, since bitter orange has not been used as an edible fruit due to its sour and bitter taste. In the case of blood orange and blond maltese jellies, the most appreciated by the panelists, results showed that reduced sugar content enhanced the fruity flavor and overall acceptability.

\section{Conclusion}

The present work showed that quality parameters, antioxidant activities, total phenolic, and total flavonoid contents of formulated jellies varied with citrus varieties. All citrus jellies were a good source of phenolic compounds and could be recommended as excellent sources of phytochemicals bringing numerous health benefits. Jellies were significantly different in colour as well as in flavour, allowing the production of a wide range of products that may meet different consumer's taste and allow fruit consumption in the offseason.

\section{Data Availability}

The data used to support the findings of this study are included within the article.

\section{Conflicts of Interest}

The authors declare that they have no conflicts of interest.

\section{Acknowledgments}

The authors are grateful to the Tunisian Canned Industries Group (GICA) especially to Mrs Sonia Mjahed for technical assistance.

\section{References}

[1] M. Scordino and L. Sabatino, "Characterization of polyphenolic profile of citrus fruit by HPLC/PDA/ESI/MS-MS," Polyphenols in Plants: Isolation, Purification and Extract Preparation, Academic Press, Cambridge, MA, USA, pp. 187-199, 2014.

[2] A. Gironés-Vilaplana, D. A. Moreno, and C. García-Viguera, "Phytochemistry and biological activity of Spanish Citrus fruits," Food \& Function, vol. 5, no. 4, pp. 764-772, 2014.

[3] B. Escudero-López, I. Cerrillo, G. Herrero-Martín et al., "Fermented orange juice: source of higher carotenoid and flavanone contents," Journal of Agricultural and Food Chemistry, vol. 61, no. 37, pp. 8773-8782, 2013.

[4] Y. Lunzhao, M. Shasha, and R. Dabing, "Phytochemistry and bioactivity of Citrus flavonoids: a focus on antioxidant, antiinflammatory, anticancer and cardiovascular protection activities," Phytochemistry Reviews, vol. 16, pp. 479-511, 2017.
[5] P. T. Gardner, T. A. C. White, D. B. McPhail, and G. G. Duthie, "The relative contributions of vitamin C, carotenoids and phenolics to the antioxidant potential of fruit juices," Food Chemistry, vol. 68, no. 4, pp. 471-474, 2000.

[6] M. Kopjar, A. Pichler, J. Turi, and V. Piližota, "Influence of trehalose addition on antioxidant activity, colour and texture of orange jelly during storage," International Journal of Food Science \& Technology, vol. 51, no. 12, pp. 2640-2646, 2016.

[7] Codex Standard for jam, jellies and mermelades (CODEX STAN 296-2009), http://www.codexalimentarius.org/input/ download/standards/.../CXS_296e.pdf.

[8] R. Riedel, B. Böhme, and H. Rohm, "Development of formulations for reduced-sugar and sugar-free agar-based fruit jellies," International Journal of Food Science \& Technology, vol. 50, no. 6, pp. 1338-1344, 2015.

[9] M. Saidani and Marzouk, "Biochemical characterization of blood orange, sweet orange, lemon, bergamot and bitter orange," Phytochemistry, vol. 62, no. 8, pp. 1283-1289, 2003.

[10] A. E. Sulieman, K. M. Y. Khodari, and Z. A. Salih, "Extraction of pectin from lemon and orange fruits peels and its utilization in jam making International," Journal of Food Science and Nutrition Engineering, vol. 3, no. 5, pp. 81-84, 2013.

[11] X.-Y. Yang, J.-X. Xie, F.-F. Wang et al., "Comparison of ascorbate metabolism in fruits of two citrus species with obvious difference in ascorbate content in pulp," Journal of Plant Physiology, vol. 168, no. 18, pp. 2196-2205, 2011.

[12] M. S. Tounsi, W. A. Wannes, I. Ouerghemmi et al., "Juice components and antioxidant capacity of four Tunisian Citrus varieties," Journal of the Science of Food and Agriculture, vol. 91, no. 1, pp. 142-151, 2011.

[13] H. Letaief, H. Zemni, A. Mliki, and S. Chebil, "Composition of Citrus sinensis (L.) Osbeck cv "Maltaise demi-sanguine» juice. A comparison between organic and conventional farming," Food Chemistry, vol. 194, pp. 290-295, 2016.

[14] J. I. Garrido, J. E. Lozano, and D. B. Genovese, "Effect of formulation variables on rheology, texture, colour, and acceptability of apple jelly: modelling and optimization," $L W T$ Food Science and Technology, vol. 62, no. 1, pp. 325-332, 2015.

[15] G. Oboh, A. O. Ademosun, M. Akinleye, O. S. Omojokun, A. A. Boligon, and M. L. Athayde, "Starch composition, glycemic indices, phenolic constituents, and antioxidative and antidiabetic properties of some common tropical fruits," Journal of Ethnic Foods, vol. 2, no. 2, pp. 64-73, 2015.

[16] M. Igual, C. Contreras, and N. Martínez-Navarrete, "Nonconventional techniques to obtain grapefruit jam," Innovative Food Science \& Emerging Technologies, vol. 11, no. 2, pp. 335-341, 2010.

[17] B. P. Pankaj, U. L. Opara, and F. A. Al-Said, "Colour measurement and analysis in fresh and processed foods: a review," Food and Bioprocess Technology, vol. 6, pp. 36-60, 2012.

[18] P. Rapisarda, M. L. Bianco, P. Pannuzzo, and N. Timpanaro, "Effect of cold storage on vitamin C, phenolics and antioxidant activity of five orange genotypes [Citrus sinensis (L.) Osbeck]," Postharvest Biology and Technology, vol. 49, no. 3, pp. 348-354, 2008.

[19] G. Xu, D. Liu, J. Chen, X. Ye, Y. Ma, and J. Shi, "Juice components and antioxidant capacity of citrus varieties cultivated in China," Food Chemistry, vol. 106, no. 2, pp. 545-551, 2008.

[20] R. Kumar, S. Vijay, and N. Khan, "Comparative nutritional analysis and antioxidant activity of fruit juices of some Citrus spp," Octa Journal of Bioscience, vol. 1, no. 1, pp. 44-53, 2013.

[21] E. Garcia-Martinez, G. Ruiz-Diaz, J. Martinez-Monzo, M. M. Camacho, N. Martinez-Navarrete, and A. Chiralt, "Jam 
manufacture with osmodehydrated fruit," Food Research International, vol. 35, no. 2, pp. 301-306, 2002.

[22] J. Ventura, F. Alarcón-Aguilar, R. Roman-Ramos et al., "Quality and antioxidant properties of a reduced-sugar pomegranate juice jelly with an aqueous extract of pomegranate peels," Food Chemistry, vol. 136, no. 1, pp. 109-115, 2013.

[23] C. M. J. Bof, R. C. Fontana, L. T. Piemolini-Barreto, and I. G. Sandri, "Effect of freezing and processing technologies on the antioxidant capacity of fruit pulp and jelly," Brazilian Archives of Biology and Technology, vol. 55, no. 1, pp. 107-114, 2012.

[24] M. Abd-Elhady, "Effect of citric acid, calcium lactate and low temperature prefreezing treatment on the quality of frozen strawberry," Annals of Agricultural Sciences, vol. 59, no. 1, pp. 69-75, 2014. 